\title{
Structural variation of the malaria- associated human glycophorin A-B-E region
}

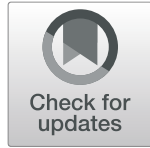

\author{
Sandra Louzada ${ }^{1,2,3}$, Walid Algady ${ }^{4}$, Eleanor Weyell ${ }^{4}$, Luciana W. Zuccherato ${ }^{5}$, Paulina Brajer ${ }^{4}$, Faisal Almalki ${ }^{4}$, \\ Marilia O. Scliar ${ }^{6}$, Michel S. Naslavsky ${ }^{6}$, Guilherme L. Yamamoto ${ }^{6}$, Yeda A. O. Duarte”, Maria Rita Passos-Bueno ${ }^{6}$, \\ Mayana Zatz ${ }^{6}$, Fengtang Yang ${ }^{1}$ and Edward J. Hollox ${ }^{4^{*}}$ (D)
}

\begin{abstract}
Background: Approximately 5\% of the human genome shows common structural variation, which is enriched for genes involved in the immune response and cell-cell interactions. A well-established region of extensive structural variation is the glycophorin gene cluster, comprising three tandemly-repeated regions about $120 \mathrm{~kb}$ in length and carrying the highly homologous genes GYPA, GYPB and GYPE. Glycophorin A (encoded by GYPA) and glycophorin B (encoded by GYPB) are glycoproteins present at high levels on the surface of erythrocytes, and they have been suggested to act as decoy receptors for viral pathogens. They are receptors for the invasion of the protist parasite Plasmodium falciparum, a causative agent of malaria. A particular complex structural variant, called DUP4, creates a GYPB-GYPA fusion gene known to confer resistance to malaria. Many other structural variants exist across the glycophorin gene cluster, and they remain poorly characterised.
\end{abstract}

Results: Here, we analyse sequences from 3234 diploid genomes from across the world for structural variation at the glycophorin locus, confirming 15 variants in the 1000 Genomes project cohort, discovering 9 new variants, and characterising a selection of these variants using fibre-FISH and breakpoint mapping at the sequence level. We identify variants predicted to create novel fusion genes and a common inversion duplication variant at appreciable frequencies in West Africans. We show that almost all variants can be explained by non-allelic homologous recombination and by comparing the structural variant breakpoints with recombination hotspot maps, confirm the importance of a particular meiotic recombination hotspot on structural variant formation in this region.

Conclusions: We identify and validate large structural variants in the human glycophorin A-B-E gene cluster which may be associated with different clinical aspects of malaria.

Keywords: Structural variation, Copy number variation, Inversion, Immune response, Glycophorin, GYPA, GYPB, GYPE, Erythrocytes, Malaria

\section{Background}

Human genetic variation encompasses single nucleotide variation, short insertion-deletions and structural variation. Structural variation can be further divided into copy number variation, tandem repeat variation, inversions and

\footnotetext{
* Correspondence: ejh33@le.ac.uk

${ }^{4}$ Department of Genetics and Genome Biology, University of Leicester, Leicester, UK

Full list of author information is available at the end of the article
}

polymorphic retrotransposons. Structural variation is responsible for much of the differences in DNA sequence between individual human genomes [1-3], yet analysis of the phenotypic importance of structural variation has lagged behind the rapid progress made in studies of single nucleotide variation [4-6]. This is mainly because of technical limitations in detecting, characterising, and genotyping structural variants both directly [7] and indirectly by imputation [8]. However, a combination of new technical

(c) The Author(s). 2020 Open Access This article is licensed under a Creative Commons Attribution 4.0 International License, which permits use, sharing, adaptation, distribution and reproduction in any medium or format, as long as you give appropriate credit to the original author(s) and the source, provide a link to the Creative Commons licence, and indicate if changes were made. The images or other third party material in this article are included in the article's Creative Commons licence, unless indicated otherwise in a credit line to the material. If material is not included in the article's Creative Commons licence and your intended use is not permitted by statutory regulation or exceeds the permitted use, you will need to obtain permission directly from the copyright holder. To view a copy of this licence, visit http://creativecommons.org/licenses/by/4.0/ The Creative Commons Public Domain Dedication waiver (http://creativecommons.org/publicdomain/zero/1.0/) applies to the data made available in this article, unless otherwise stated in a credit line to the data. 
approaches using genome sequencing data to detect structural variation and larger datasets allowing more robust imputation of structural variation have begun to show that some structural variants at an appreciable frequency in populations do indeed contribute to clinically-important phenotypes $[9,10]$.

One example of a potentially clinically-important structural variant is a variant at the human glycophorin gene locus called DUP4, which confers a reduced risk of severe malaria and protection against malarial anemia [11-13]. The glycophorin gene locus consists of three $120 \mathrm{~kb}$ tandem repeats sharing $\sim 97 \%$ identity, each repeat carrying a closely-related glycophorin gene, starting from the centromeric end: glycophorin E (GYPE), glycophorin B (GYPB) and glycophorin A (GYPA) [14, 15]. Large tandem repeats, like the glycophorin locus, are prone to genomic rearrangements, and indeed the DUP4 variant is a complex variant that generates a GYPBGYPA fusion gene, with potential somatic variation in fusion gene copy number $[11,12]$. This fusion gene is expressed and can be detected on the cell surface as the Dantu blood group [11], and erythrocytes carrying this blood group are known to be resistant to infection by Plasmodium falciparum in cell culture [16].

How the DUP4 variant mediates resistance to severe malaria is not fully understood. It is well established that both glycophorin A and glycophorin B are expressed on the surface of human erythrocytes and interact with the EBA-145 receptor and the EBL-1 receptor, respectively, of $P$. falciparum [17]. We might expect that direct disruption of ligand-receptor interactions by a glycophorin B-glycophorin A fusion receptor might be responsible for the protective effect of the DUP4 variant. However, recent data suggest that alteration of receptor-ligand interactions is not important. Instead, it seems likely that DUP4 is associated with more complex alterations in the protein levels at the red blood cell surface resulting in increased red blood cell tension, mediating its protective effect against $P$. falciparum invasion [18]. Given the size of effect of the DUP4 variant in protection against malaria (odds ratio $\sim 0.6$ ) and the frequency of the allele (up to $13 \%$ in Tanzania), it is clinically potentially very significant, although it appears to be geographically restricted to East Africa [11].

Because of the clinical importance of the DUP4 glycophorin variant, and how it can lead to insights on the mechanisms underlying malaria, it is timely to identify and characterise other structural variants in the glycophorin region. Previously, other structural variants in the glycophorin region have been identified in the $1000 \mathrm{Ge}$ nomes project samples by using sequence read depth analysis of $1.6 \mathrm{~kb}$ bins combined with a Hidden Markov Model approach to identify regions of copy number gain and loss [11]. This built upon identification of extensive
$\mathrm{CNV}$ in this genomic region by array $\mathrm{CGH}$ [19] and indeed by previous analysis of rare MNS (Miltenberger) blood groups, such as $\mathrm{M}^{\mathrm{K}}$, caused by homozygous deletion of both GYPA and GYPB [14]. The structural variants that were previously identified were classified as DUP and DEL representing gain and loss of sequence read depth respectively. Although only DUP4 has been found to be robustly associated with clinical malaria phenotypes, it is possible that some of the other structural variants are also protective, but are either rare, recurrent, or both rare and recurrent, making imputation from flanking SNP haplotypes and genetic association with clinical phenotypes challenging.

It is important, therefore, to extend this catalogue of glycophorin structural variants at this locus and robustly characterise their nature and likely effect on the number of fulllength and fusion glycophorin genes. In this study we characterise and validate glycophorin structural variants from a larger and geographically diverse set of individuals. To detect copy number changes in the glycophorin genomic region, we use sequence read depth analysis of 3234 diploid genomes from across the world, followed by direct analysis of structural variants using fibre-FISH and breakpoint mapping using paralogue-specific PCR and Sanger sequencing. This will allow future development of robust yet simple PCR-based assays for each structural variant and detailed analysis of the phenotypic consequences of particular structural variants on malaria infection and other traits. We also begin to examine the pattern of distribution of different variants across the world, and the pattern of structural variation breakpoints in relation to their mechanism of generation and known meiotic recombination hotspots within the region. Together, this allows us to gain some insight into the evolutionary context of the extensive structural variation at the glycophorin locus.

\section{Results}

Structural variation using sequence read depth analysis Previous work by us and others has shown that unbalanced structural variation - that is, variation that causes a copy number change - can be effectively discovered by measuring the relative depth of sequence reads across the glycophorin region $[11,12]$. We analysed a total of 3234 diploid genomes from four datasets spanning the globe - the 1000 Genomes phase 3 project set, the Gambian Genome Variation project, the Simons diversity project, and the Brazilian genomes project. We took a different sequence read depth approach to that previously used, counting the reads that map to the glycophorin repeat region and dividing by the number of reads mapping to a nearby non-structurally variable region to normalise for read depth. By analysing each cohort of diploid genomes as a group, we could identify outliers where a higher value indicated a potential 
duplication or more complex gain of sequence, and lower values indicated a potential deletion (Supplementary Fig. 1). Sequence read depth was analysed in $5 \mathrm{~kb}$ windows across each of the outlying diploid genomes to identify and classify the structural variant.

Since structural variant calling had been previously done on the 1000 Genomes project cohort, this provided a useful comparison to assess our approach. We analysed samples from this cohort and identified five distinct deletions carried by 88 individuals, and 16 distinct duplications carried by 34 individuals (Table 1 ) that were all previously identified (Supplementary data). We also identified a new duplication variant, termed DUP29 (a duplication of $G Y P B$ ), that had not been identified previously in that cohort. However, as expected, smaller duplications, most notably DUP1, were not detected by our approach. We extended our analysis to Gambian genomes and identified 51 samples with DEL1 or DEL2 variants, and DEL16, subsequently characterized in the Brazilian cohort below. Two samples were heterozygous for the duplication DUP5.

Both 1000 Genomes and Gambian Genome Variation samples have been sequenced to low depth. High depth sequencing will allow more robust identification of structural variation by improving the signal/noise ratio of sequence read depth analysis. We analysed the publically available high-depth data from the Simons Diversity Project for glycophorin variation. From the 273 individuals, 4 different deletion types were carried by 13 individuals, and 3 different duplication types were carried by 5 individuals. A novel deletion, DEL15 was identified which deleted part of GYPB and part of GYPE in an individual from Bergamo in Italy, and a novel duplication was observed in three individuals from Papua New Guinea, termed DUP30 and duplicating the GYPB gene. Another duplication variant, DUP8, is the largest variant found so far. It involves a duplication involving two glycophorin repeat units, $240 \mathrm{~kb}$ in total, and creates an extra full length GYPB gene and a GYPE-GYPA fusion gene (Table 1).

Further samples sequenced to high coverage diploid genomes from Brazil were analysed, which, given the extensive admixture from Africa in the Brazilian population, are likely to be enriched for glycophorin variants from Africa. Three new duplication variants (DUP33DUP35) and three new deletion variants were found (DEL16, DEL17, DEL18), two of which of which delete the GYPB gene (Table 1).

\section{Fibre-FISH analysis of structural variants}

Sequence read depth analysis shows copy number gain and loss with respect to the reference genome to which the sequence reads are mapped, but it does not determine the physical structure of the structural variant. For all glycophorin structural variants we identified in the 1000 Genomes samples (with the exception of the smaller DUP22), matched lymphoblastoid cell lines were available allowing us to use fibre-FISH in order to determine the physical structure of these variants. In all cases, a set of multiplex FISH probes, with each probe being visualised with a unique fluorochrome, was used so that the orientation and placement of the repeats could be identified (Fig. 1). The repeated nature of the glycophorin region means that the green and red probes from the $G Y P B$ repeat cross-hybridise with the other repeats, with the GYPA repeat is distinguishable from the GYPB and GYPE repeats by a $16 \mathrm{~kb}$ insertion resulting in a small gap of signal in the green probe (Fig. 1).

For most variants the fibre-FISH results confirmed the structure previously predicted [11] and expected if the variants had been generated by non-allelic homologous recombination (NAHR) between the glycophorin repeats (Figs. 2 and 3). However, three variants showed a complex structure that could not be easily predicted from the sequence read depth analysis. The DUP4 variant shows a complex structure and has been described previously [12] . Two other structural variants (DUP5 and DUP26) also showed complex patterns of gains or losses, and fibre-FISH clearly shows the physical structure of the variant, including inversions.

The more frequent of these two complex structural variants, DUP5, seems to be restricted to Gambia, as it is found once in the GWD population from the $1000 \mathrm{Ge}$ nomes project and twice in the Jola population from the Gambian Genome Variation project (Table 1). Sequence read depth analysis suggests that DUP5 has two extra copies of GYPE and an extra copy of GYPB, with an additional duplication distal of GYPA outside the glycophorin repeated region (Fig. 4a). Fibre-FISH analysis on cells from an individual carrying the DUP5 variant (HG02585) confirmed heterozygosity of the variant, with one allele being the reference allele, and revealed, for the first time, that the variant allele presents a complex pattern of duplication and rearrangement, with part of the fosmid (pseudocoloured in white) mapping distal to GYPA being translocated into the glycophorin repeated region, adjacent to the green-coloured fosmid (Fig. 4b). Alternative fibre-FISH analysis using an additional fosmid probe mapping distally, and labelled in red, confirmed this (Fig. 4c). The pattern of FISH signals occurring distally to the translocation suggests that the immediately adjacent glycophorin repeat is inverted. To distinguish the distal end of the GYPB repeat from the distal end of the GYPE repeat, a pink-coloured probe from a short GYPE-repeat-specific PCR product was also used for fibre-FISH, and clearly shows only a single copy of the distal end of the GYPB repeat in the DUP5 variant, at the same position as the reference. The predicted 


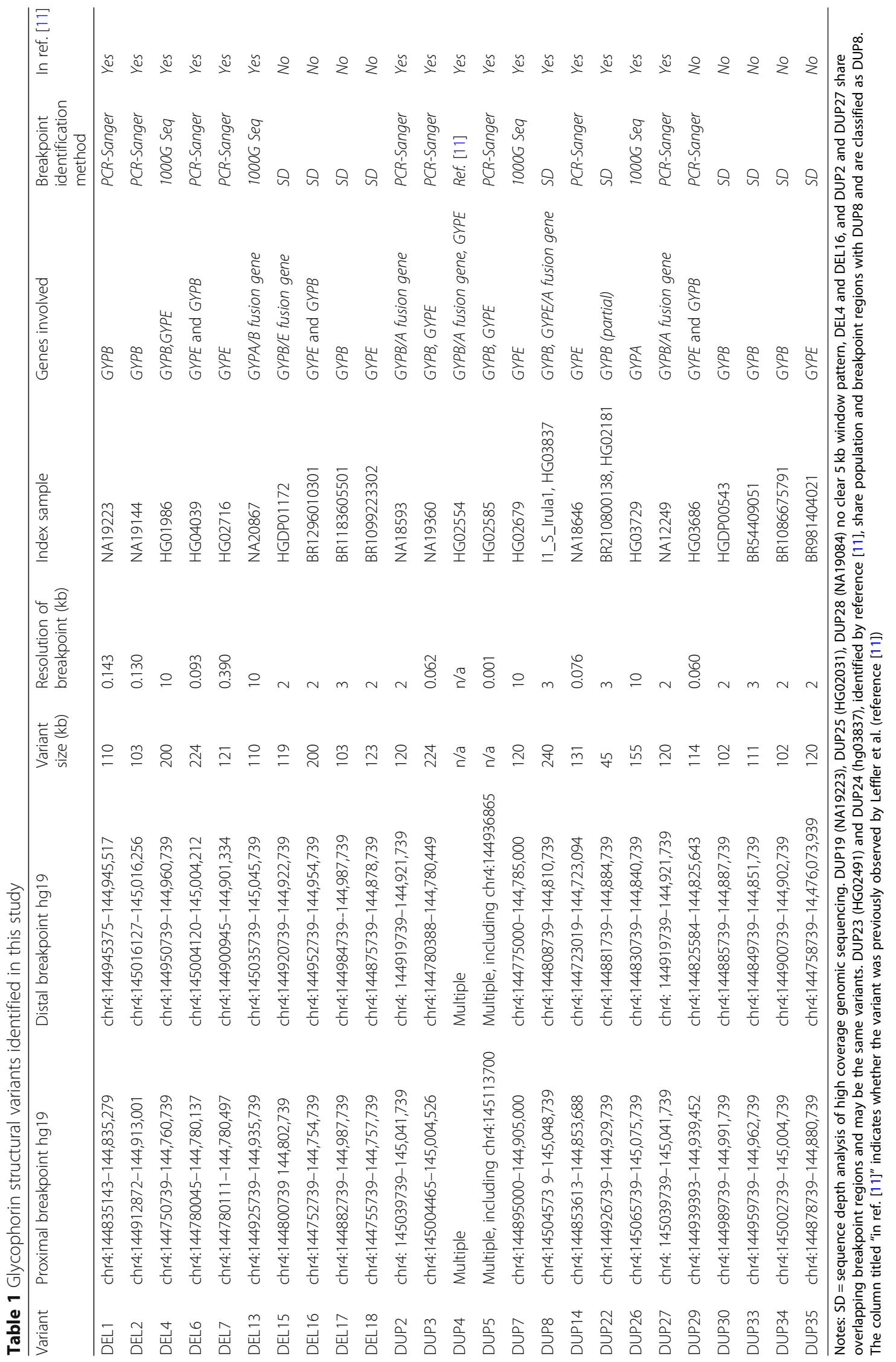




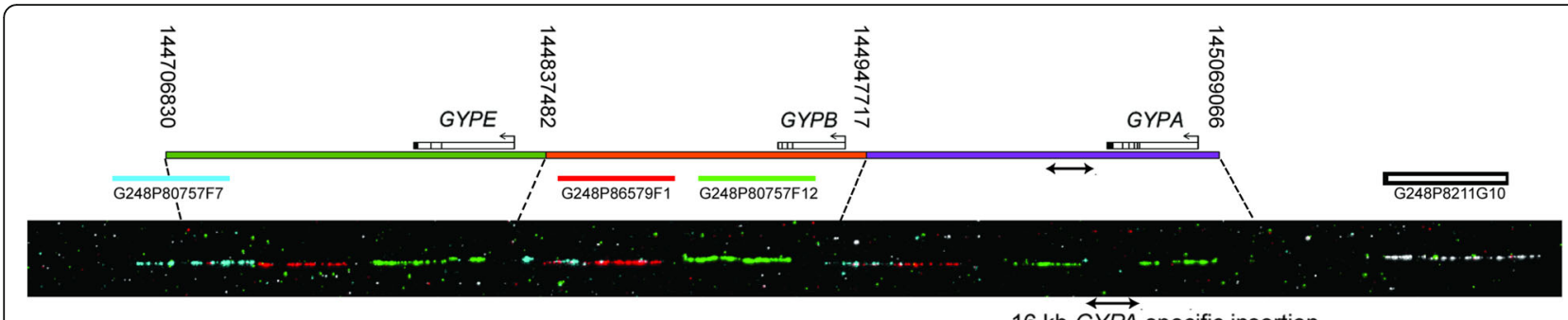

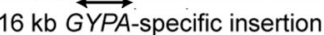

Fig. 1 Structure of the glycophorin reference allele. A representation of the reference allele assembled in the GRCh37/hg19 assembly is shown, with the three distinct paralogous $\sim 120 \mathrm{~kb}$ repeats of the glycophorin region coloured green, orange and purple, carrying GYPE, GYPB and GYPA respectively. Numbers over the start and end of each paralogue represent coordinates in chromosome 4 GRCh37/hg19 assembly. Coloured bars represent fosmids used as probes in fibre-FISH, with the fosmid identification number underneath. The lower black panel is an example fibre FISH image of this reference haplotype (from sample HG02585). The fibre-FISH image is scaled approximately to match the reference above it, with approximate boundaries between glycophorin repeats shown as dashed lines

breakpoint between the non-duplicated sequence distal to GYPA and duplicated sequence within the duplicated region was amplified by PCR and Sanger sequenced, confirming that the non-duplicated sequence was fused to an inverted GYPB repeat sequence (Fig. 4d). The model suggested by the fibre-FISH and breakpoint analysis is consistent with the overall pattern of sequence depth changes observed (Fig. 4a). The sequence outside the glycophorin repeat corresponds to an ERV-MaLR long terminal retroviral element, but the sequence inside the glycophorin repeat sequence is not, suggesting that non-allelic homologous recombination was not the mechanism for formation of this breakpoint. However, there is a 4 bp microhomology (GTGT) between the two sequences, suggesting that microhomology-mediated end joining could be a mechanism for formation of this variant.

The DUP26 variant was observed once, in sample HG03729, an Indian Telugu individual from the United Kingdom, sequenced as part of the 1000 Genomes project. Sequence read depth analysis predicts an extra copy of the glycophorin repeat, partly derived from the GYPB repeat and partly from the GYPA repeat (Fig. 4e). The fibre-FISH shows an extra repeat element that is GYPBlike at the proximal end and GYPA-like at the distal end, and carries the GYPA gene. This structure is unlikely to have been generated by a straightforward single NAHR event, and we were unable to resolve the breakpoint at high resolution.

\section{Breakpoint analysis of structural variants}

Defining the precise breakpoint of the variants can allow a more accurate prediction of potential phenotypic effects of each variant by assessing, for example, whether a glycophorin fusion gene is formed or whether key regulatory sequences are deleted. We used two approaches to define breakpoints. The first approach identified the two $5 \mathrm{~kb}$ windows that spanned the change in sequence read depth at both ends of the deletion or duplication, and by designing PCR primers to specifically amplify across the junction fragment (Fig. 5a, b), variant-specific PCR amplification produces an amplicon that can be sequenced (Fig. 5c). After Sanger sequencing the amplicons, the breakpoint can be shown to be where a switch occurs between paralogous sequence variants (PSVs) that map to different glycophorin repeats (Fig. 5d), supporting the model that a NAHR mechanism is responsible for generating these structural variants (Fig. 5e). The second approach makes use of high depth sequencing. The two $5 \mathrm{~kb}$ windows spanning the change in sequence read depth are again identified and sequence read depth calculated in $1 \mathrm{~kb}$ windows to further refine the breakpoint. The sequence alignment spanning the two $1 \mathrm{~kb}$ windows is examined manually for paired sequence reads where the gap between the aligned pairs is consistent with the size of the variant, or where both sequence pairs align but one aligns with multiple sequence mismatches.

With the exception of DEL4, DUP7 and DUP26, where only low-coverage sequence was available, all other breakpoints could be localised to between $10 \mathrm{~kb}$ and 1 bp. For most variants, the breakpoints occur between genes resulting in loss or gain of whole genes, and therefore likely to show gene dosage effect. It is known that DUP4 results in a GYPB-GYPA fusion gene that codes for the Dantu blood group, and a fusion gene is also predicted for DUP2, DUP8 and DEL15. The DUP2 variant generates a GYPB-GYPA fusion gene comprising exons 1-2 of GYPB and exons 4-7 of GYPA corresponding to the $\mathrm{St}^{\mathrm{a}}$ (GP.Sch) blood group [20]. Breakpoint analysis of NA12249, the sample carrying the DUP27 variant, showed that DUP27 breakpoint is in the same intron as DUP2 (Supplementary Fig. 2). By using a variant-specific PCR primer pair (Supplementary Table 1) followed by Sanger sequencing, we show the exact breakpoint is complex, as the GYPA-like sequence does not show a 


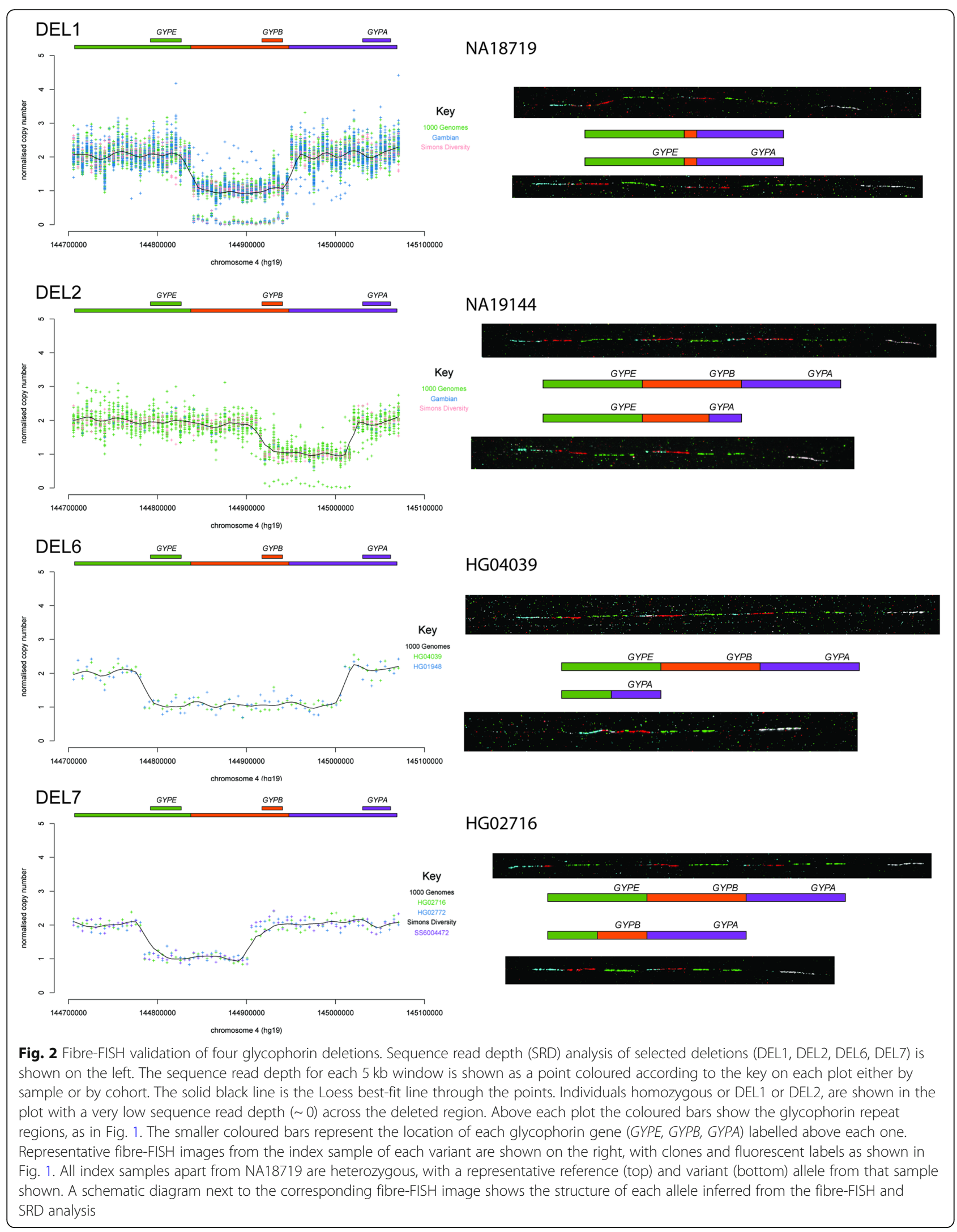




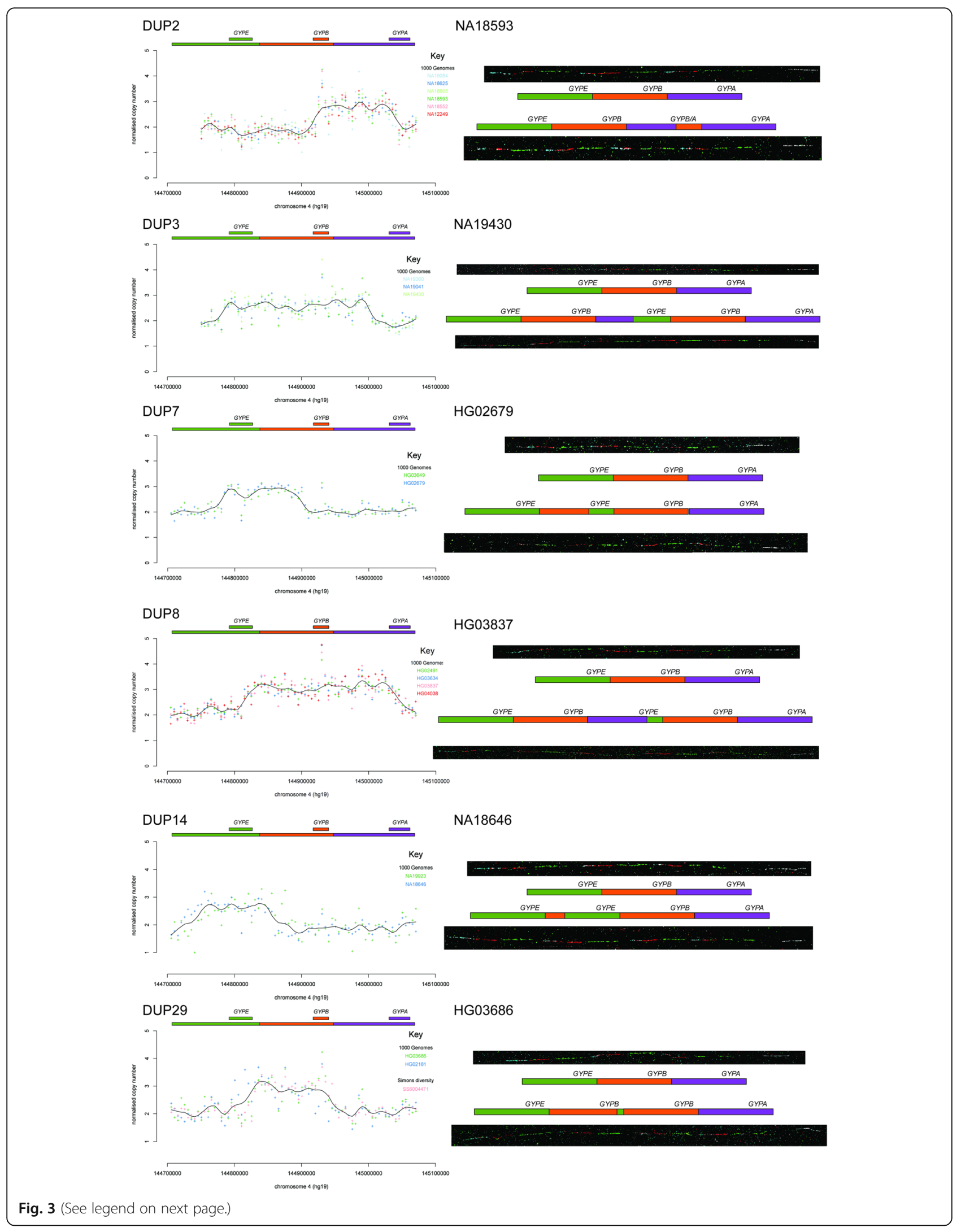


(See figure on previous page.)

Fig. 3 Fibre-FISH validation of six glycophorin duplications. Sequence read depth (SRD) analysis of selected duplications (DUP2, DUP3, DUP7, DUP8, DUP14 and DUP29) is shown on the left. The sequence read depth for each $5 \mathrm{~kb}$ window is shown as a point coloured according to the key on each plot either by sample or by cohort. The solid black line is the Loess best-fit line through the points. Above each plot the coloured bars show the glycophorin repeat regions, as in Fig. 1. The smaller coloured bars represent the location of each glycophorin gene (GYPE, GYPB, GYPA) labelled above each one. Representative fibre-FISH images from the index sample of each variant are shown on the right, with clones and fluorescent labels as shown in Fig. 1, with an additional green-labelled PCR product specific to the glycophorin E repeat for HG03686. All index samples are heterozygous, with a representative reference and variant allele from that sample shown. A schematic diagram next to the corresponding fibre-FISH image shows the structure of each allele inferred from the fibre-FISH and SRD analysis

simple switch to $G Y P B$-like sequence but rather shows a pattern of alternate patches of GYPB- and GYPA-like sequence, suggesting a history of gene conversion events between the glycophorin repeat regions (Supplementary Fig. 2). Although the variants are the same across most of the sequence, two variants are GYPB-like in DUP2 and GYPA-like in DUP27. This can be explained either by two different recombination events generating the DUP2 and DUP27 variants, or their being exactly the same variant, generated by the same recombinational event, but distinguished by a later gene conversion event on DUP27. At present, therefore, it is unclear whether DUP27 is exactly the same variant as DUP2, and sequencing of more examples of both variants is needed.

The DUP8 variant is predicted to generate a fusion gene consisting of exon 1 of GYPE and exons 2-7 of GYPA, and the DEL15 variant is predicted to combine the first two exons of GYPB with the final three exons of GYPE. It is unlikely that DUP8 has a phenotype, given the involvement of the $5^{\prime}$ end of GYPE, which is not expressed. The DEL15 variant is predicted to generate a $G Y P B-G Y P E$ peptide, and the breakpoint between exon 1 of GYPB and exon 2 of GYPE is consistent with the variant that causes the rare $U$ - blood group phenotype, resulting in a lack of expression of glycophorin B in homozygotes $[21,22]$. It has been shown that the U- blood group can also be caused by the more common DEL1 and DEL2 alleles, both of which also result in GYPB deletion [23]. Other variants involve breakpoints within 1 $\mathrm{kb}$ of a gene coding region and could potentially affect expression levels of the neighbouring gene.

\section{Mechanism of formation of structural variants}

The pattern of deletions and duplications observed is consistent with a simple NAHR mechanism of formation for the variants (Fig. 5e), with the exception of DUP5 and DUP26. We investigated whether the breakpoints we had found co-localised with known meiotic recombination hotspots previously determined by anti-DMC1 ChIP-Seq of the testes of five males [24] . Importantly, the recombination hotspot dataset mapped hotspots in individuals carrying different alleles of the highly-variable PRDM9 protein, a key determinant of recombination hotspot activity, with different alleles activating different recombination hotspots. The glycophorin region contains one hotspot regulated by the PRDM9 A allele, common in Europeans (allele frequency 0.84), and the PRDM9 $\mathrm{C}$ allele, common in sub-Saharan Africans (allele frequency 0.13). In our data we found no breakpoints coincident with the PRDM9 A allele hotspot but 4 breakpoints coincident with the PRDM9 $\mathrm{C}$ allele hotspot (Fig. 6), as observed previously [11]. The overlap between the PRDM9 $\mathrm{C}$ allele hotspot and the structural variant breakpoints is statistically significant (two-tailed Fisher's exact test, $p=0.012$ ) and reflects the observation that there are more different rare structural variants in sub-Saharan African populations, with high frequencies of the $\mathrm{C}$ allele, than in European populations where the $C$ allele is almost absent (allele frequency 0.01) [26]. Consistent with this, the four variants where breakpoints span the PRDM9 C allele hotspot (DUP3, DUP7, DEL6, DEL7) are found in the sub-Saharan African or Admixed American populations (Table 2).

\section{Discussion}

We have characterised a number of structural variants at the human glycophorin locus (Supplementary Fig. 3). These are almost always large deletions or duplications involving the loss or gain of one or occasionally two glycophorin repeat regions of about $120 \mathrm{~kb}$. These losses and gains are consistent with an origin by non-allelic homologous recombination (NAHR) between glycophorin repeats, with particular involvement of the PRDM9 C allele, which is at appreciable frequencies in African populations and directs high recombination rates at its cognate recombination hotspots. A more complex variant, termed DUP5, was also characterised, and was shown to be an inversion-duplication with a breakpoint suggesting generation by at least one microhomology-mediated end-joining event involving DNA sequence outside the glycophorin repeat region. Similarly, DUP26 is a complex variant that is unlikely to have been generated by a single NAHR event.

Only DEL1, DEL2 and DUP2 are frequent variants. Both DEL1 and DEL2 delete the GYPB gene and it is tempting to speculate that their high frequency in African populations and populations with African admixture is due to selection. Indeed, erythrocytes from individuals 


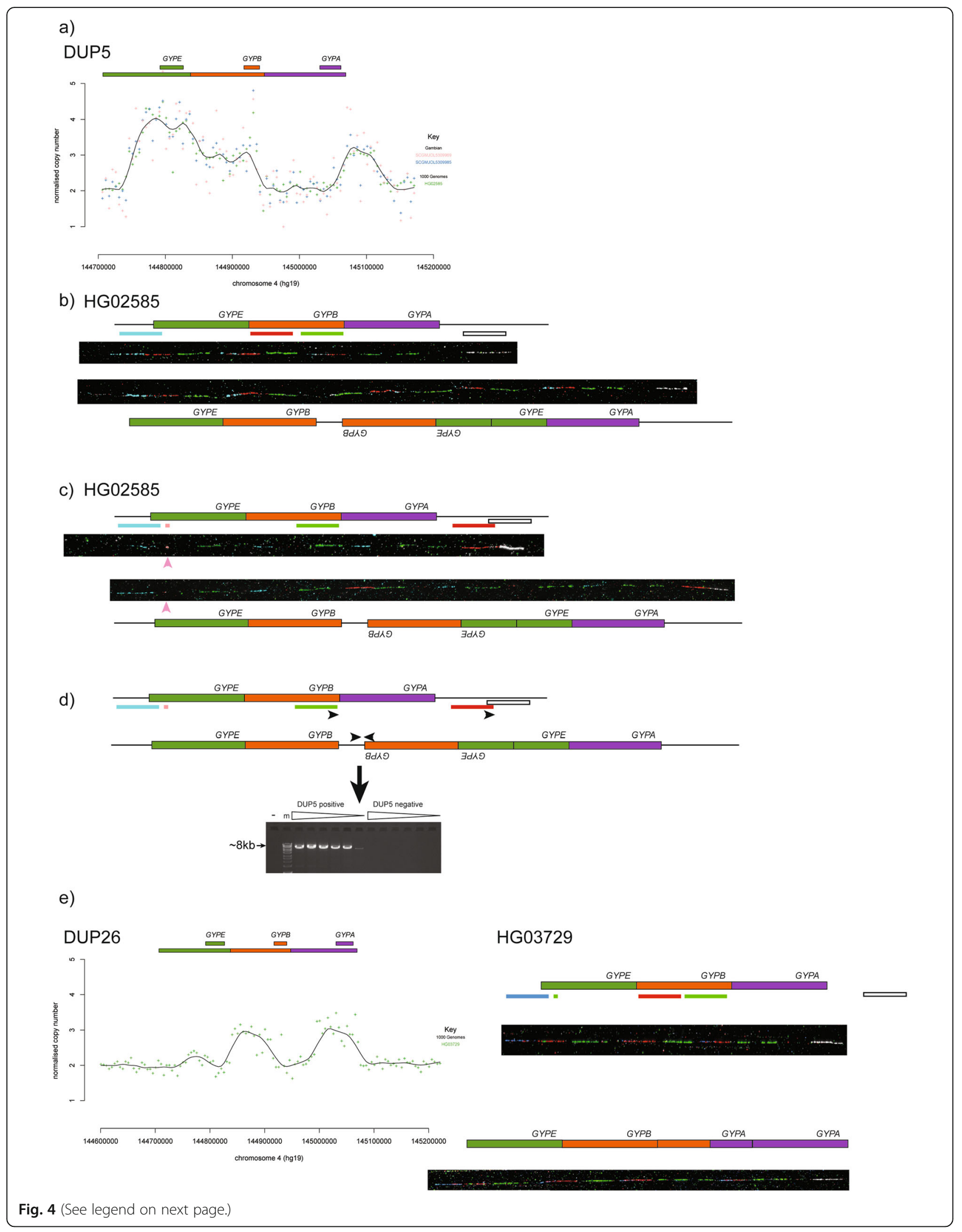




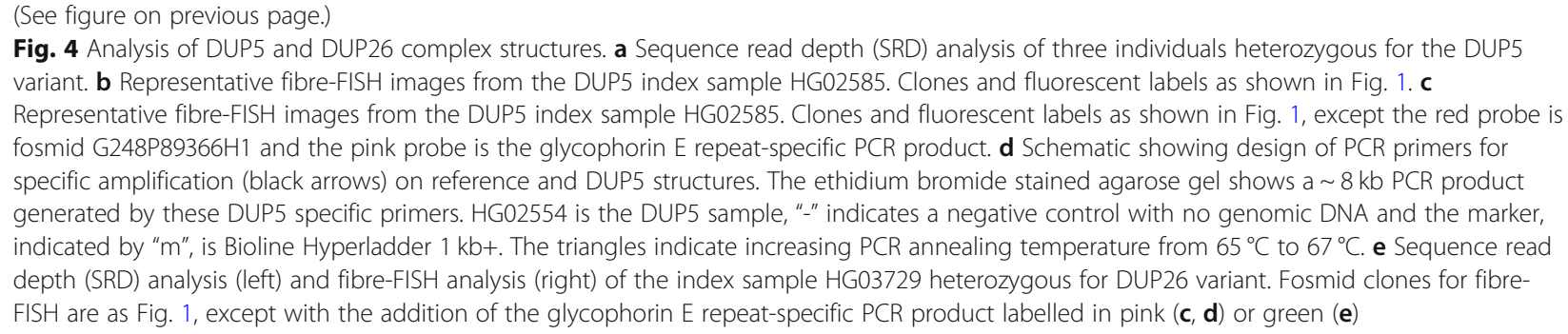

showing the U- blood group and therefore homozygous for GYPB deletion are resistant to P. falciparum infection in vitro [16, 23, 27]. However, the absence of epidemiological evidence for any protective effect against malaria argues that malaria is not the cause of this selection, so this remains speculation. DUP2 is at notable frequencies particularly in East Asia, and is predicted to generate a GYPB-GYPA fusion gene corresponding to the $\mathrm{St}^{\mathrm{a}}$ blood group, which is known to be at appreciable frequencies in East Asia [28, 29]. In this region, malaria infections are caused by Plasmodium falciparum as well as Plasmodium vivax; alternatively, this fusion gene may facilitate glycophorins acting as a decoy receptor for other pathogens, such as hepatitis A virus [30, 31]. Previous work has shown that DUP2 has arisen on multiple haplotype backgrounds [11], which suggests a large East Asian population panel is need for future accurate imputation.

Other variants seem either to be geographically localised (for example DUP5) or very rare and detected as singletons in our dataset. This suggests that analysis of other large genomic datasets will discover further unique glycophorin structural variants, and that much glycophorin structural variation is individually rare but collectively more frequent, leading to challenges in imputing glycophorin structural variation from SNP GWAS data.

In contrast to other studies, we used a three-step approach to determine copy number. We used read counts over the whole glycophorin region to detect samples with duplications (more than expected number of reads) and deletions (fewer than expected number of reads). We then used window-based analysis of sequence read depth and paralogue-specific allele-specific PCR and Sanger sequencing to refine copy number breakpoints. Finally, we validated the structure of selected variants using fibre-FISH. Our approach has the advantage that it does not rely on a sudden change in sequence read depth for CNV detection by a HMM, which may be compromised by poor mappability of some sequence reads in the breakpoint region and assumptions about the absence of somatic variation, with the consequence that the expected copy number reflecting an integer value. However, our approach cannot detect smaller copy number changes, with an estimated threshold of $60 \mathrm{~kb}$ for heterozygous changes of and $\sim 30 \mathrm{~kb}$ for homozygous changes. This is because, for these sizes, the relative increase or decrease in the number of mapped reads at the glycophorin region is likely to be below the threshold used to call a copy number change. We also make assumptions that each variant is a simple deletion or duplication with one breakpoint, unless clearly shown to be otherwise by fibre-FISH, such as for DUP5. Long read DNA sequencing will help to clarify the variation in this region further and will be able to resolve the extent to which our assumptions have been valid.

Previous work has shown that the DUP4 variant carried by the sample HG02554 shows somatic mosaicism, leading to the suggestion that somatic mosaicism may be a feature of glycophorin structural variants [12] . In this study, our fibre-FISH analyses identified no other potential somatic variants at the glycophorin locus, showing that it is not a common feature of $1000 \mathrm{Ge}-$ nomes lymphoblastoid cell lines nor of non-DUP4 variants. This suggests that somatic mosaicism is either restricted to DUP4 variants in general or restricted to the particular DUP4 sample HG02554, although a more thorough investigation of high coverage genome sequences will be needed to address this issue.

\section{Conclusion}

We identify nine new structural variants at the human glycophorin locus, characterise breakpoints and mutational mechanisms for known and novel structural variants, and show that recombination hotspot activity has influenced the nature of the structural variants observed. For some of the variants, targeted high coverage sequence using very long reads will help refine some of the breakpoints. Further efforts are needed to characterise the phenotypic effects of particular variants involving gain, loss and fusion of glycophorin genes.

\section{Methods}

\section{Samples analysed in this study}

For this study we analysed whole genome sequences from 2492 individuals from the 1000 Genomes Project, 391 individuals from the Gambian Genomes project, 274 individuals from the Simons Diversity Project, and 1325 individuals from the Brazilian Genomes project. Of these, the 1000 Genomes project samples analysed here 


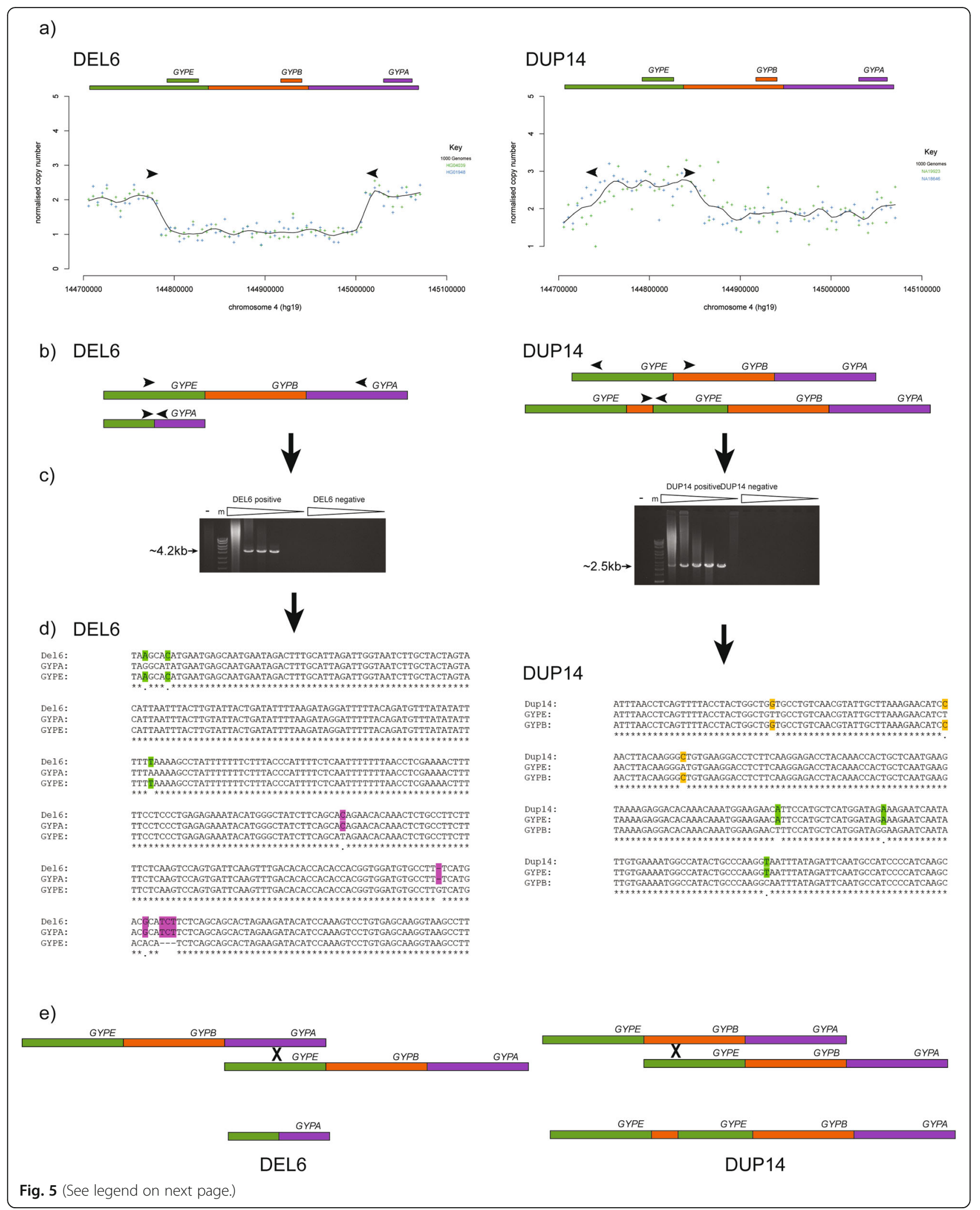


(See figure on previous page.)

Fig. 5 Examples of refining breakpoints of a deletion (DEL6) and a duplication (DUP14). a Sequence read depth analysis, indicating position of PCR primers (not to scale). $\mathbf{b}$ Variant model, showing position of primers on reference and variant. c Agarose electrophoresis of long PCR products using variant-specific primers indicated in b). "-" indicates a negative control with no genomic DNA and the marker, indicated by " $m$ ", is Bioline Hyperladder $1 \mathrm{~kb}+$. The triangles indicate increasing PCR annealing temperature from $58^{\circ} \mathrm{C}$ to $67^{\circ} \mathrm{C}$. $\mathbf{d}$ Multiple sequence alignment of the variant-specific PCR product, with homologous sequence on the GYPA repeat and the GYPE repeat. GYPE-specific variants are in green, GYPArepeat-specific variants are in purple. e A model of the generation of the variants by NAHR

had been previously analysed specifically for glycophorin copy number variation using different approaches [11].

\section{Sequencing data}

Sequence alignment files (bam format) from four cohorts (1000 Genomes Project ENA accession number PRJNA262923) with a mean coverage of 7.4x [32], Simons Diversity Project ENA accession number PRJEB9586 with a mean coverage of 43x [33], and the Gambian Genome Diversity project mean coverage $4 x$, ENA study IDs ERP001420, ERP001781, ERP002150, ERP002385) [34] were downloaded from the European Nucleotide Archive or from the International Genome Sample Resource site http://www.internationalgenome. org/data-portal/ [35]. We also analysed Brazilian sequence alignment files from the SABE (Health, Wellbeing and Aging) study [36] and a sample of cognitively healthy octogenarians enrolled at the Human Genome and Stem Cell Research Center (80+), with a mean coverage of 30x for 1325 individuals generated at $\mathrm{Hu}-$ man Longevity Inc. (HLI, San Diego, California) [37].

DNA sequences from the 1000 Genomes project and the Simons diversity project had been previously aligned to reference GRCh37 (hg19) to generate the alignment bam files. The exception is sample NA18605, which was previously sequenced at high coverage [38] downloaded as paired-end Illumina sequences in fastq format (ENA sample accession number SAMN00001619), and aligned to GRCh37 using standard approaches: FastQC v0.11.5 and Cutadapt v01.11 to trim reads and adapters, mapping using BWA-MEM v0.7.15, processing of the BAM files using SAMtools v1.8, local realignment was done using GATK v3.6 and duplicate reads marked using Picard v.1 and removed using SAMtools. Samples from the Brazilian genomes and the Gambian genome diversity project had been aligned to GRCh38.

Throughout this paper, all loci are given using GRCh37 reference genome coordinates. For analyses on GRCh38 alignments, genome coordinates were translated from the GRCh37 coordinates using the Liftover tool within the UCSC Genome Browser [39].

\section{Structural variant detection}

For each sample, we used SAMtools (SAMtools view -c -F 4) [24] on indexed bam files to count mapped reads to the glycophorin region (chr4:144745739-145,069,133) and a reference region chr4:145516270-145,842,585. The reference region has no segmental duplications, and is absent from copy number variation according to the gold standard track of the database of Genomic Variants (DGV) [40]. A ratio of the number or reads mapping to the glycophorin region to the number of reads mapping to the reference region allows an estimate of the total increase or decrease of sequence depth spanning the

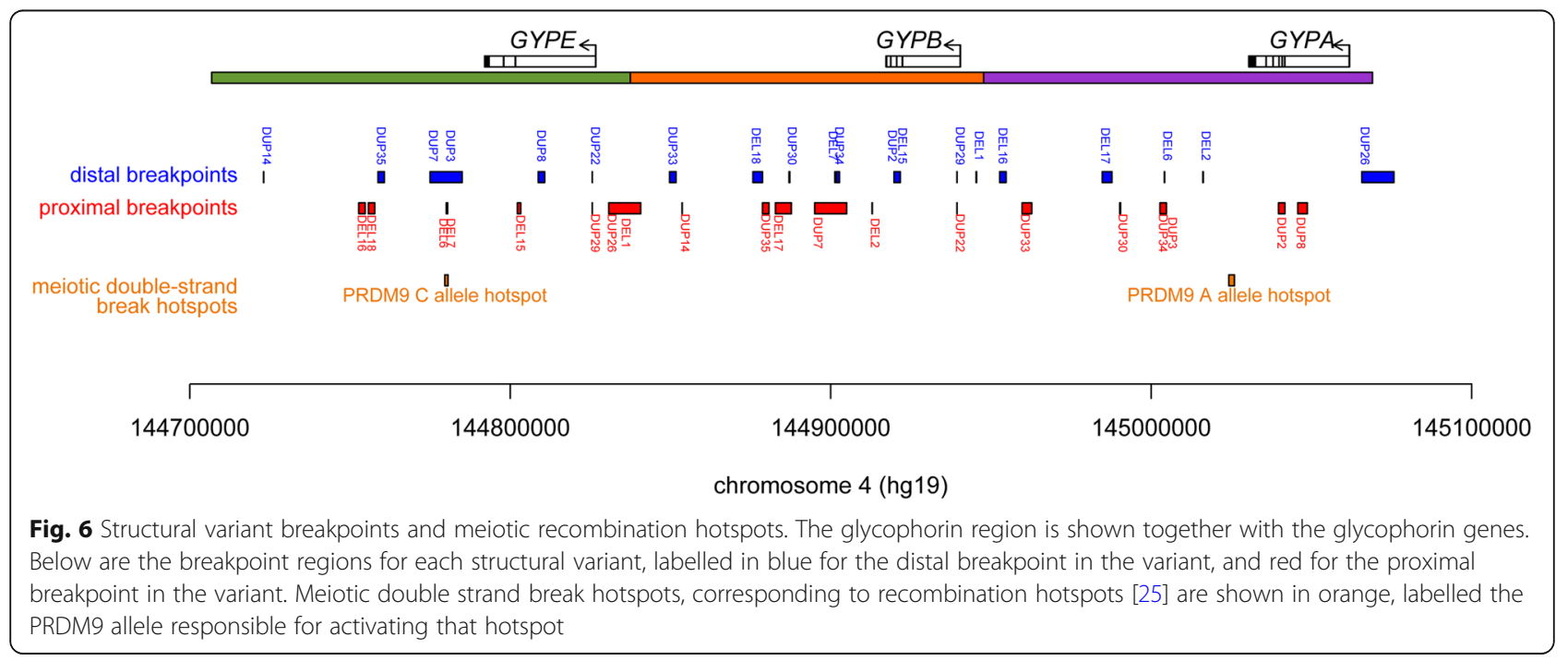


Table 2 Global distributionof glycophorin structural variants

\begin{tabular}{|c|c|c|c|c|c|c|c|c|}
\hline \multirow[t]{2}{*}{ Continental grouping } & \multicolumn{5}{|c|}{1000 Genomes } & \multirow{2}{*}{$\begin{array}{l}\text { Gambian } \\
\text { AFR }\end{array}$} & \multirow{2}{*}{$\begin{array}{l}\text { Simons } \\
\text { ALL }\end{array}$} & \multirow{2}{*}{$\begin{array}{l}\text { Brazilian } \\
\text { AMR }\end{array}$} \\
\hline & EUR & AFR & SAS & EAS & AMR & & & \\
\hline Total number of chromosomes & 600 & 640 & 386 & 606 & 258 & 782 & 546 & 2650 \\
\hline DEL1 & 0 & 53 & 0 & 1 & 1 & 55 & 7 & 19 \\
\hline DEL2 & 0 & 26 & 0 & 0 & 2 & 2 & 4 & 12 \\
\hline DEL4/16 & 0 & 1 & 0 & 0 & 0 & 1 & 0 & 3 \\
\hline DEL6 & 0 & 0 & 1 & 0 & 1 & 0 & 0 & 0 \\
\hline DEL7 & 0 & 2 & 0 & 0 & 0 & 0 & 1 & 0 \\
\hline DUP2/27 & 0 & 1 & 1 & 11 & 1 & 0 & 0 & 7 \\
\hline DUP3 & 0 & 4 & 0 & 0 & 0 & 0 & 0 & 0 \\
\hline DUP5 & 0 & 1 & 0 & 0 & 0 & 2 & 0 & 0 \\
\hline DUP7 & 0 & 1 & 0 & 0 & 1 & 0 & 0 & 2 \\
\hline DUP8 & 0 & 0 & 4 & 0 & 0 & 0 & 1 & 2 \\
\hline DUP29 & 0 & 0 & 1 & 0 & 0 & 0 & 1 & 0 \\
\hline DUP22 & 0 & 0 & 0 & 1 & 0 & 0 & 1 & 1 \\
\hline DUP30 & 0 & 0 & 0 & 0 & 0 & 0 & 3 & 0 \\
\hline DUP35 & 0 & 0 & 0 & 0 & 0 & 0 & 0 & 2 \\
\hline
\end{tabular}

Notes: Variants observed more than once are included. The full list of individuals with different glycophorin variants, together with their population of origin, is available as supplementary data

glycophorin region (reflecting copy number gain or copy number loss, respectively). Because the size of the regions used for sequence read count is $\sim 320 \mathrm{~kb}$, and spans the whole glycophorin region, we would not expect copy number losses within the region to necessarily show read depth ratios of 0 or 0.5 for homozygous or heterozygous losses respectively, unless the whole 320 $\mathrm{kb}$ region is deleted. For similar reasons we would not expect homozygous or heterozygous copy number gains to show values of 1.5 or 2 . Following plotting these data for each cohort on a histogram, observation of distinct clusters (supplementary Fig. 1) allowed us to identify samples with a ratio below 0.9 as potential copy number losses and those above 1.1 as potential copy number gains. The main peak of the histogram below 0.9 is at 0.8 , and above 1.1 is at 1.2 , suggesting that the copy number gains or losses identified in those peaks in the histograms are $\sim 100 \mathrm{~kb}$ and heterozygous. Samples showing rations of $\sim 0.6$ for losses or $\sim 1.4$ for gains represent either larger copy number changes in the heterozygous state, or homozygous $\sim 100 \mathrm{~kb}$ copy number alterations.

For the samples with potential copy number gains and losses, the mapped reads were counted across the glycophorin region in $5 \mathrm{~kb}$ non-overlapping windows, normalised to the average read count across the whole region, then normalised to diploid copy number. The resulting values were plotted across the genomic region. The presence and nature of structural variants were assessed by examination of quality of the plots, ensuring that copy number gains and losses and a consistent gain or loss of sequence read depth across a contiguous region. Variants were grouped and called as the same variant by plotting together with a reference sample for that variant. For the 1000 Genomes project, 6 samples were identified as harbouring copy number gains or losses across the glycophorin region, but failed to pass this subsequent $5 \mathrm{~kb}$ window step because sequence read depth was noisy across the region and no consistent region showing loss or gain of read depth was seen. For the Simons Diversity Project samples, 114 potential deletions were identified, much more than in other cohorts (Supplementary Fig. 1). Inspection of these plots showed that 101 of these samples showed a high level of sequence depth ratio noise, and a small apparent $\sim 15 \mathrm{~kb}$ deletion at the GYPE gene. This deletion was not found previously by others [11] by us in any other cohort, and coincides with a region of low mappability, suggesting that this may be an artefact caused either by particular filtering conditions or the particular genome assembly (GRCh37d5) that includes decoy sequences. These 101 samples were treated as being homozygous for the reference structure.

Twenty samples had been sequenced both by the 1000 Genomes project and the Simons' Diversity Project. Our copy number calls were identical between both replicate genome sequences across all 20 samples, with three samples showing a copy number variant. The twenty samples included samples that showed the putative $15 \mathrm{~kb}$ deletion in the Simons diversity samples, but not in the 1000 Genomes samples, further supporting our assertion that this was an artefact. 


\section{Fibre-FISH}

The probes used in this study included four WIBR-2 fosmid clones selected from the UCSC Genome Browser GRCh37/hg19 assembly and a 3632-bp PCR product that is specific for the glycophorin E repeat [12] . Probes were made by amplification with GenomePlex Whole Genome Amplification Kits (Sigma-Aldrich) as described previously [33] . Briefly, the purified fosmid DNA and the PCR product were amplified and then labeled as follow: G248P86579F1, G248P89366H1 and glycophorin E repeat-specific PCR product were labelled with digoxigenin-11-dUTP, G248P8211G10 was labelled with biotin-16-dUTP, G248P85804F12 was labeled with DNP11-dUTP and G248P80757F7 was labeled with Cy5dUTP. All labeled dUTPs were purchased from Jena Bioscience.

The preparation of single-molecule DNA fibers by molecular combing and fiber-FISH was as previously published [33], with the exception of post-hybridization washes, which consisted of three 5 min washes in $2 \times$ $\mathrm{SSC}$ at $42{ }^{\circ} \mathrm{C}$, instead of two $20 \mathrm{~min}$ washes in $50 \%$ formamide $/ 50 \% 2 \times \mathrm{SSC}$ at room temperature.

\section{Breakpoint analysis using PCR and sanger sequencing}

Using the $5 \mathrm{~kb}$ window sequence read count data, PCR primers were designed so that a PCR product spanned the predicted breakpoints for each deletion and duplication. The 3' nucleotide for each PCR primer was designed to match uniquely to a particular glycophorin repeat, and to mismatch the other two glycophorin repeats. Annealing specificity of the PCR primer was enhanced by incorporating a locked nucleic acid at that particular 3' position of the PCR primer [21]. Longrange PCR amplification used $10 \mathrm{ng}$ genomic DNA in a final volume of $25.5 \mu \mathrm{l}$, including $0.5 \mu \mathrm{l}$ of each $10 \mu \mathrm{M}$ primer, 0.075 U Pfu DNA polymerase, 0.625 U Taq DNA polymerase, and $2.25 \mu \mathrm{l}$ of PCR buffer ( $45 \mathrm{mM}$ Tris- $\mathrm{HCl}$ (pH 8.8), $11 \mathrm{mM}$ ammonium sulphate, $4.5 \mathrm{mM}$ magnesium chloride, $6.7 \mathrm{mM}$ 2-mercaptoethanol, $4.4 \mathrm{mM}$ EDTA (pH 8.0), $113 \mu \mathrm{g} / \mathrm{mL}$ non-acetylated Bovine Serum Albumin (BSA) $\left(\right.$ Ambion $^{\odot}$ ) and $1 \mathrm{mM}$ of each dNTP (Promega) [41]). The reaction was thermal cycled as follows: $94{ }^{\circ} \mathrm{C} 1$ min, followed by 20 cycles of $94{ }^{\circ} \mathrm{C}$ for $15 \mathrm{~s}, \mathrm{x}^{\circ} \mathrm{C}$ for 10 min, followed by 15 cycles of $94{ }^{\circ} \mathrm{C}$ for $15 \mathrm{~s}, \mathrm{x}^{\circ} \mathrm{C}$ for $10 \mathrm{~min}$ $+15 \mathrm{~s}$ for each successive cycle, followed by a final extension at $72{ }^{\circ} \mathrm{C}$ for $10 \mathrm{~min}$, where $\mathrm{x}$ is the annealing temperature for a particular primer pair shown in supplementary Table 1. PCR products were purified using agarose gel electrophoresis [42] and Sanger sequenced using standard approaches. PCR primers are shown in supplementary Table 1. Multiple alignments with paralogous reference sequences used MAFFT v7 [43] available at the EMBL-EBI Job Dispatcher framework [44]. A breakpoint was called in the transition region between three paralogous sequence variants corresponding to one glycophorin repeat and three paralogous sequence variants corresponding to the alternative glycophorin repeat.

\section{Breakpoint analysis using high depth sequences}

For particular variants, copy number breakpoints were refined by inspecting sequence read depth in $1 \mathrm{~kb}$ windows spanning the likely breakpoints identified by the $5 \mathrm{~kb}$ window analysis. Changes in read depth were then confirmed directly using the Integrative Genome Viewer [45].

\section{Nomenclature of variants}

We used the same nomenclature as reference [11] when our variant could be identified as the same variant in the same sample from the 1000 Genomes project. In some instances, we could not distinguish particular singleton variants called from more common called variants. For example, DUP27 carried by sample NA12249 could not easily be distinguished from the more frequent DUP2, and DUP24 carried by HG04038 could not be distinguished from DUP8. Other variants, which either had not been unambiguously identified in the 1000 Genomes previously or were identified in other sample cohorts, were given DEL or DUP numbers following on from variants catalogued previously. Variant data are available on dbVar https://www.ncbi.nlm.nih.gov/dbvar/ accession number nstd177. A list of the samples carrying particular variants is also included as supplementary data.

\section{Analysis of recombination hotspots}

Previously published data on hotspot location and type [25] was converted to BED format and intersected with the breakpoint locations in BED format using BEDTools $\mathrm{v}$ 2.28.0 [46]. The statistical significance of the overlap was calculated using the fisher command in BEDTools, which uses a Fisher's exact test on the number of overlaps observed between two BED files.

\section{Supplementary information}

Supplementary information accompanies this paper at https://doi.org/10. 1186/s12864-020-06849-8.

\footnotetext{
Additional file 1. Supplementary Table 1

Additional file 2: Supplementary Fig. 1. Histograms of sequence read depths of the glycophorin region. Histograms of normalised sequence read depths of the four cohorts used for this study, with red indicating putative deletions and blue putative duplications. The Brazilian Genomes samples are new to this study, all other samples have publicly available genome sequence. a) 1000 Genomes Project (2492 individuals) Gambian Genome Variation Project (391 individuals). b) Simons Diversity Project (274 individuals). c) Brazilian Genomes Project (1325 individuals)

Additional file 3: Supplementary Fig. 2. Sequence alignment of DUP2 and DUP27 variants across their breakpoints. The figure shows an alignment of the DUP2 variant sequence and the DUP27 variant sequence from the index samples NA18593 and NA12249 respectively. Also aligned are the reference GYPB and GYPA sequences. Variable nucleotides in the alignment are coloured depending on whether they
} 
are the same as GYPA in that position (purple) or GYPB in that position (orange). Red arrows indicate differences between the two variants.

Additional file 4: Supplementary Fig. 3. Summary of the positions of deletion and duplication variants in this study. The complex DUP5 rearranged variant is not shown.

Additional file 5. Supplementary data.

\section{Abbreviations}

CNV: Copy number variation; FISH: Fluorescent in-situ hybridisation; GWAS: Genomewide association study; HMM: Hidden Markov Model; PCR: Polymerase chain reaction

\section{Acknowledgements}

This research used the ALICE High Performance Computing Facility at the University of Leicester. We thank Rachael Madison for technical support.

\section{Authors' contributions}

Study design and funding: WA, MZ, FY and EJH. Fibre-FISH analysis and interpretation SL, PB, EY, EJH. Sequence analysis: EW, LWZ, FA, EJH. Breakpoint analysis: WA, LWZ, PB, EJH. Data provision: MOS, MSN, GLY, YAOD, MRP-B, MZ. EJH wrote the paper, with input from SL and FY. All authors read and approved the final manuscript.

\section{Funding}

This work was funded by SACB PhD studentships to WA and FA and Wellcome Trust grant WT098051 (F.Y. and S.L.). The funding agencies had no role in the design, analysis or interpretation of data.

\section{Availability of data and materials}

Variant data is available on dbVar https://www.ncbi.n/m.nih.gov/dbvar/ accession number nstd177. Genome sequence data for the 1000 Genomes project samples and Gambian Genome Variation Project samples are available at https://www.internationalgenome.org/data. Brazilian genome data corresponding to the region analysed in this paper are available on request.

\section{Ethics approval and consent to participate}

For the Brazilian samples, the SABE (Health, Wellbeing and Aging) study was approved by the FSP-USP Institutional Review Board. A signed informed consent form was obtained from all participants. Other data (Simons Diversity Project, 1000 Genomes Project, Gambian Genomes Project) and samples (1000 Genomes project) are publicly available.

\section{Consent for publication}

Not applicable.

\section{Competing interests}

The authors declare that they have no competing interests.

\section{Author details}

${ }^{1}$ Wellcome Sanger Institute, Hinxton, Cambridge, UK. ${ }^{2}$ Present address: Laboratory of Cytogenomics and Animal Genomics (CAG), Department of Genetics and Biotechnology, University of Trás-os-Montes and Alto Douro (UTAD), Vila Real, Portugal. ${ }^{3}$ Present address: BioISI - Biosystems \& Integrative Sciences Institute, Faculty of Sciences, University of Lisboa, Lisbon, Portugal. ${ }^{4}$ Department of Genetics and Genome Biology, University of Leicester, Leicester, UK. ${ }^{5}$ Department of Pathology, Faculty of Medicine, Universidade Federal de Minas Gerais, Belo Horizonte, Brazil. ${ }^{6}$ Human Genome and Stem Cell Research Center, Department of Genetics and Evolutionary Biology, Instituto de Biociências, Universidade de São Paulo, São Paulo, Brazil. ' ${ }^{\text {SSchool }}$ of Nursing, Universidade de São Paulo, São Paulo, Brazil.

Received: 7 January 2020 Accepted: 18 June 2020

Published online: 29 June 2020

\section{References}

1. Sudmant PH, Rausch T, Gardner EJ, Handsaker RE, Abyzov A, Huddleston J, et al. An integrated map of structural variation in 2,504 human genomes. Nature. 2015;526:75-81.
2. Zarrei M, MacDonald JR, Merico D, Scherer SW. A copy number variation map of the human genome. Nat Rev Genet. 2015;16:172-83.

3. Hehir-Kwa JY, Marschall T, Kloosterman WP, Francioli LC, Baaijens JA, Dijkstra $\mathrm{L}$, et al. A high-quality human reference panel reveals the complexity and distribution of genomic structural variants. Nat Commun. 2016;7:12989.

4. Hollox EJ, Hoh B-P. Human gene copy number variation and infectious disease. Hum Genet. 2014;133:1217-33.

5. Usher CL, McCarroll SA. Complex and multi-allelic copy number variation in human disease. Brief Funct Genomics. 2015;14:329-38.

6. Huddleston J, Eichler EE. An incomplete understanding of human genetic variation. Genetics. 2016;202:1251-4.

7. Cantsilieris S, Western PS, Baird PN, White SJ. Technical considerations for genotyping multi-allelic copy number variation (CNV), in regions of segmental duplication. BMC Genomics. 2014;15:329.

8. Handsaker RE, Van Doren V, Berman JR, Genovese G, Kashin S, Boettger LM, et al. Large multiallelic copy number variations in humans. Nat Genet. 2015; 47:296-303.

9. Sekar A, Bialas AR, de Rivera H, Davis A, Hammond TR, Kamitaki N, et al. Schizophrenia risk from complex variation of complement component 4. Nature. 2016;530:177-83.

10. Raffield LM, Ulirsch JC, Naik RP, Lessard S, Handsaker RE, Jain D, et al. Common a-globin variants modify hematologic and other clinical phenotypes in sickle cell trait and disease. PLoS Genet. 2018;14:e1007293.

11. Leffler EM, Band G, Busby GBJ, Kivinen K, Le QS, Clarke GM, et al. Resistance to malaria through structural variation of red blood cell invasion receptors. Science. 2017;356.

12. Algady W, Louzada S, Carpenter D, Brajer P, Färnert A, Rooth I, et al. The malaria-protective human glycophorin structural variant DUP4 shows somatic mosaicism and association with hemoglobin levels. Am J Hum Genet. 2018;103:769-76.

13. Ndila CM, Uyoga S, Macharia AW, Nyutu G, Peshu N, Ojal J, et al. Human candidate gene polymorphisms and risk of severe malaria in children in Kilifi, Kenya: a case-control association study. Lancet Haematol. 2018;5:e333-45.

14. Vignal A, Rahuel C, London J, Cherif Zahar B, Schaff S, Hattab C, et al. A novel gene member of the human glycophorin a and $B$ gene family. Molecular cloning and expression. Eur J Biochem. 1990;191:619-25.

15. Onda M, Kudo S, Fukuda M. Genomic organization of glycophorin a gene family revealed by yeast artificial chromosomes containing human genomic DNA. J Biol Chem. 1994;269:13013-20.

16. Field SP, Hempelmann E, Mendelow BV, Fleming AF. Glycophorin variants and Plasmodium falciparum: protective effect of the Dantu phenotype in vitro. Hum Genet. 1994;93:148-50.

17. Jaskiewicz E, Jodłowska M, Kaczmarek R, Zerka A. Erythrocyte glycophorins as receptors for Plasmodium merozoites. Parasit Vectors. 2019;12:317.

18. Kariuki SN, Marin-Menendez A, Introini V, Ravenhill BJ, Lin Y-C, Macharia A, et al. Red blood cell tension controls Plasmodium falciparum invasion and protects against severe malaria in the Dantu blood group. bioRxiv. 2018:475442.

19. Conrad DF, Pinto D, Redon R, Feuk L, Gokcumen O, Zhang Y, et al. Origins and functional impact of copy number variation in the human genome. Nature. 2010;464:704-12.

20. Louzada S, Komatsu J, Yang F. Fluorescence in situ hybridization onto DNA fibres generated using molecular combing. In: Fluorescence In Situ Hybridization (FISH) Application Guide. Verlag: Springer; 2017. p. 275-93.

21. Latorra D, Campbell K, Wolter A, Hurley JM. Enhanced allele-specific PCR discrimination in SNP genotyping using $3^{\prime}$ locked nucleic acid (LNA) primers. Hum Mutat. 2003;22:79-85.

22. Daniels G. Human blood groups: Wiley; 2008.

23. Gassner C, Denomme GA, Portmann C, Bensing KM, Mattle-Greminger MP, Meyer S, et al. Two Prevalent $\sim 100-k b$ GYPB Deletions Causative of the GPB-Deficient Blood Group MNS Phenotype S-s-U- in Black Africans. TMH. 2020:1-11.

24. Li H, Handsaker B, Wysoker A, Fennell T, Ruan J, Homer N, et al. The sequence alignment/map format and SAMtools. Bioinformatics. 2009;25: 2078-9.

25. Pratto F, Brick K, Khil P, Smagulova F, Petukhova GV, Camerini-Otero RD. DNA recombination. Recombination initiation maps of individual human genomes. Science. 2014;346:1256442.

26. Berg IL, Neumann R, Sarbajna S, Odenthal-Hesse L, Butler NJ, Jeffreys AJ. Variants of the protein PRDM9 differentially regulate a set of human meiotic recombination hotspots highly active in African populations. Proc Natl Acad Sci U S A. 2011;108:12378-83. 
27. Rahuel C, London J, Vignal A, Ballas SK, Cartron JP. Erythrocyte glycophorin B deficiency may occur by two distinct gene alterations. Am J Hematol. 1991;37:57-8.

28. Anstee DJ, Mawby WJ, Parsons SF, Tanner MJ, Giles CM. A novel hybrid sialoglycoprotein in Sta positive human erythrocytes. J Immunogenet. 1982; 9:51-5.

29. Madden HJ, Cleghorn TE, Allen FH, Rosenfield RE, Mackeprang M. A note on the relatively high frequency of ST-a on the red blood cells of ORIENTALS, and report of a third example of anti-ST-a. Vox Sang. 1964;9:502-4.

30. Baum J, Ward RH, Conway DJ. Natural selection on the erythrocyte surface. Mol Biol Evol. 2002;19:223-9.

31. Sánchez G, Aragonès L, Costafreda Ml, Ribes E, Bosch A, Pintó RM. Capsid region involved in hepatitis a virus binding to glycophorin a of the erythrocyte membrane. J Virol. 2004;78:9807-13.

32. 1000 Genomes Project Consortium, Auton A, Brooks LD, Durbin RM, Garrison EP, Kang HM, et al. A global reference for human genetic variation. Nature. 2015;526:68-74.

33. Mallick S, Li H, Lipson M, Mathieson I, Gymrek M, Racimo F, et al. The Simons genome diversity project: 300 genomes from 142 diverse populations. Nature. 2016;538:201-6.

34. Malaria Genomic Epidemiology Network. Insights into malaria susceptibility using genome-wide data on 17,000 individuals from Africa, Asia and Oceania. Nat Commun. 2019;10:1-19.

35. Fairley S, Lowy-Gallego E, Perry E, Flicek P. The international genome sample resource (IGSR) collection of open human genomic variation resources. Nucleic Acids Res. 2020;48:D941-7.

36. Barbosa $A R$, Souza JMP, Lebrão ML, Laurenti R, de FN MM. Functional limitations of Brazilian elderly by age and gender differences: data from SABE survey. Cad Saude Publica. 2005;21:1177-85.

37. Telenti A, Pierce LCT, Biggs WH, di lulio J, Wong EHM, Fabani MM, et al. Deep sequencing of 10,000 human genomes. Proc Natl Acad Sci U S A. 2016;113:11901-6.

38. Lan T, Lin H, Zhu W, Laurent TCAM, Yang M, Liu X, et al. Deep wholegenome sequencing of 90 Han Chinese genomes. Gigascience. 2017;6:1-7.

39. Kent WJ, Sugnet CW, Furey TS, Roskin KM, Pringle TH, Zahler AM, et al. The human genome browser at UCSC. Genome Res. 2002;12:996-1006.

40. MacDonald JR, Ziman R, Yuen RKC, Feuk L, Scherer SW. The database of genomic variants: a curated collection of structural variation in the human genome. Nucleic Acids Res. 2014;42(Database issue):D986-92.

41. Jeffreys AJ, Neumann R, Wilson V. Repeat unit sequence variation in minisatellites: a novel source of DNA polymorphism for studying variation and mutation by single molecule analysis. Cell. 1990;60:473-85.

42. Ma H, Difazio $S$. An efficient method for purification of $P C R$ products for sequencing. BioTechniques. 2008;44:921-3.

43. Katoh K, Standley DM. MAFFT multiple sequence alignment software version 7: improvements in performance and usability. Mol Biol Evol. 2013; 30:772-80

44. Li W, Cowley A, Uludag M, Gur T, McWilliam H, Squizzato S, et al. The EMBLEBI bioinformatics web and programmatic tools framework. Nucleic Acids Res. 2015:43:W580-4.

45. Thorvaldsdóttir H, Robinson JT, Mesirov JP. Integrative genomics viewer (IGV): high-performance genomics data visualization and exploration. Brief Bioinform. 2013;14:178-92.

46. Quinlan AR, Hall IM. BEDTools: a flexible suite of utilities for comparing genomic features. Bioinformatics. 2010;26:841-2.

\section{Publisher's Note}

Springer Nature remains neutral with regard to jurisdictional claims in published maps and institutional affiliations.

Ready to submit your research? Choose BMC and benefit from:
- fast, convenient online submission
- thorough peer review by experienced researchers in your field
- rapid publication on acceptance
- support for research data, including large and complex data types
- gold Open Access which fosters wider collaboration and increased citations
- maximum visibility for your research: over 100M website views per year
At BMC, research is always in progress.
Learn more biomedcentral.com/submissions

